\title{
Anticancer pyridines induce G2/M arrest and apoptosis via p53 and JNK upregulation in liver and breast cancer cells
}

\author{
VASILIS P. ANDROUTSOPOULOS and DEMETRIOS A. SPANDIDOS
}

Laboratory of Clinical Virology, Medical School, University of Crete, Voutes, Heraklion 71003, Crete, Greece

Received October 27, 2017; Accepted November 28, 2017

DOI: 10.3892/or.2017.6116

\begin{abstract}
In the present study, the synthesis and biological evaluation of one novel pyridine and one novel pyridone anticancer compound is reported. The compounds 6-(2,4-dimetho xyphenyl)-4-(3,4-methylenedioxyphenyl)-1H-pyridin-2-one (1) and 2-(2,4-dimethoxyphenyl)-4-(3,4-methylenedioxyphenyl) pyridine (2) were synthesized from a chalchone precursor. 1 was more active than 2 in inhibiting the proliferation of MCF-7 and HepG2 cells, whereas HepG2 cells were more sensitive to the antiproliferative activity of these compounds compared with MCF-7 cells. The lowest $\mathrm{IC}_{50}$ value was noted for compound 1 in HepG2 cells $\left(\mathrm{IC}_{50}=4.5 \pm 0.3 \mu \mathrm{M}\right)$. The mechanism of action involved induction of $\mathrm{G} 2 / \mathrm{M}$ arrest and apoptosis. Both 1 and 2 further induced downregulation of the cell cycle-associated protein cyclin D1 and upregulation of the cell cycle inhibitors p53 and p21 and the apoptosis-associated protein JNK in HepG2 cells. Compound 1 was further shown to induce phosphorylation of JNK in HepG2 cells. These results demonstrate promising cytostatic effects for the two novel anticancer compounds in human cancer cells.
\end{abstract}

\section{Introduction}

Liver cancer is the third most common cancer in the world and breast cancer the most frequently encountered gynecological malignancy. The one-year survival rate for liver cancer is particularly low, whereas breast cancer exhibits a favorable survival rate when diagnosed early $(1,2)$. Current chemotherapeutic options for liver cancer include the alkylating agent cisplatin and the topoisomerase inhibitor doxorubicin, while the antimetabolite 5-fluorouracil and the taxane docetaxel are the chemotherapeutic drugs used frequently to treat breast cancer patients. Although the use of these chemotherapeutic regimens is well established, the major drawback encountered is their limited specificity for

Correspondence to: Dr Vasilis Androutsopoulos, Department of Clinical Virology, Medical School, University of Crete, Voutes, Heraklion 71003, Crete, Greece

E-mail: androuts@uoc.gr

Key words: breast cancer, liver cancer, pyridines, apoptosis, JNK, cell cycle arrest the tumor site. Hence, in the past two decades considerable effort has been made to develop strategies that will target malignant cells more specifically. Notably compounds that inhibit the cell cycle of cancer cells and act in a cytostatic fashion, such as the EGFR inhibitor gefitinib have been investigated (3).

Natural products have played an essential role in the quest for developing chemotherapeutic agents with enhanced specificity and potency. Chalcones, which constitute an important class of natural products that belongs to the flavonoid family, display a wide range of biological activities, such as cytotoxic, anticancer, anti-inflammatory and anti-microbial activities (4). Specifically, chalcones that contain methoxy group substitutions have shown cytotoxic activities against the cancer cell lines ACHN, H460, HCT116, Panc1 and Calu1 (5). 2-Hydroxy-2,3,4',6-tetramethoxychalcone was found to demonstrate in vitro antiproliferative activity via upregulation of p53 and p21 and downregulation of $\mathrm{p}-\mathrm{Cdc} 2$ and $\mathrm{p}-\mathrm{Rb}$ in A549 cells and in vivo antitumor activity in A549 xenografts (6). However, various chalcones are known to be phototransformed from trans into cis isomers, in solution such as 3-hydroxy-3'-methylchalcone, and it is believed that the phototransformed cis analogues show more antitumorigenic activity than the original transform $(7,8)$. This presents difficulties in evaluating the efficacy of these compounds as more than one isomers are present in solution.

To overcome the non-specific isomerization of chalcones, we synthesized one pyridone, namely 6-(2,4-dimethoxyphenyl)-4(3,4-methylenedioxyphenyl)-1H-pyridin-2-one (compound 1) and one pyridine, 2-(2,4-dimethoxyphenyl)-4-(3,4-methylenedioxyphenyl)pyridine (compound 2) starting from a chalcone precursor (Fig. 1B). We further evaluated the anticancer properties of compounds 1 and 2 in MCF-7 human breast adenocarcinoma and HepG2 liver hepatoblastoma cells.

\section{Materials and methods}

Reagents. The reagents for chemical synthesis were from Merck KGa (Darmstadt, Germany) and Thermo Fisher Scientific, Inc., (Waltham, MA, USA). Media and cell culture reagents were from Merck KGa. Western blotting reagents were obtained from Bio-Rad Laboratories Ltd., (Watford, Hertfordshire, UK). Primary antibodies for cyclin D1, p53, p21 and NF- $\mathrm{B}$ were from Santa Cruz Biotechnology, Inc., (Dallas, TX, USA), whereas primary antibodies for JNK and p-JKN ${ }^{\text {Thr183/Tyr185 }}$ were from Upstate Biotechnology, Inc. (Lake 
Placid, NY, USA) and for $\beta$-actin from Merck KGa. Secondary antibodies used were from Santa Cruz Biotechnology, Inc.

Synthesis. The general procedure involved the synthesis of a chalcone precursor by a classical Claisen-Schmidt condensation reaction. This compound was used to prepare a pyridone compound that was in turn converted into a pyridine via hydrogenolysis from a chlorinated pyridine precursor. The exact synthetic strategy of these two compounds will be published in a separate article.

Cell culture. MCF-7 and HepG2 cells were maintained in RPMI-1640 with phenol red and DMEM respectively, containing $10 \%$ fetal calf serum and $2 \mathrm{mM}$ glutamine. The cells were passaged every 2 to 3 days using trypsin EDTA (0.25\%).

MTT assay. HepG2 and/or MCF-7 cells were seeded at a density of $10^{4}$ cells $/ \mathrm{ml}$ in 96-well flat-bottomed plates. After $24 \mathrm{~h}$, the medium was carefully removed, and 1 and/or 2 were added to $200 \mu \mathrm{l}$ medium to obtain a final concentration of not more than $0.1 \%$ (v/v) DMSO. The cells were then allowed to grow for $96 \mathrm{~h}$ at $37^{\circ} \mathrm{C}$. The medium was removed, and fresh medium containing MTT $(0.4 \mathrm{mg} / \mathrm{ml})$ was added to each well for $3 \mathrm{~h}$. The formazan product generated by the viable cells was solubilised with $150 \mu \mathrm{l}$ of DMSO. The plates were vortexed, and the absorbance at $540 \mathrm{~nm}$ was determined using a Spectra Max M5/M5 ${ }^{\mathrm{e}}$ microplate reader (Molecular Devices, LLC, Sunnyvale, CA, USA). The results were expressed as the percentage of proliferation compared with the control wells, and the $\mathrm{IC}_{50}$ was calculated using GraphPad Prism software. The dose range was in serial dilutions, namely $20,10,5,2.5$, $1.25,0.625,0.3125,0.156$ and $0.078 \mu \mathrm{M}$.

Flow cytometry. HepG2 and/or MCF-7 cells were pretreated with 1, 2 and/or $0.1 \%$ DMSO (negative control) for $24 \mathrm{~h}$. The medium was aspirated and the cells were washed with cold PBS, fixed in $70 \%$ ethanol and stored at least for $2 \mathrm{~h}$ at $-20^{\circ} \mathrm{C}$. The cells were then resuspended in PI solution $(70 \mu \mathrm{g} / \mathrm{ml}$ in PBS) containing 13 Kunitz units of RNase and incubated at $37^{\circ} \mathrm{C}$ for $30 \mathrm{~min}$. Fluorescence was measured with a FACS Beckman Coulter, Inc., (Oakley Court, Buckinghamshire, UK) flow cytometer. The instrument was calibrated, and the laser was aligned using fluorescent beads and a flow check protocol prior to each sample run. The doublets were separated from single cells in the $\mathrm{G} 2 / \mathrm{M}$ phase by gating. At least 10,000 events were acquired. The induction of apoptosis was measured by the proportion of the cells in the subG1 phase.

Western blot analysis. HepG2 and/or MCF-7 cells were trypsinized and resuspended in $200 \mu$ llysis solution (Merck KGa) containing protease inhibitor cocktail (Merck KGa) and DTT (1 mM). A total of $20 \mu 1$ of each sample was mixed with loading buffer (containing 5\% mercaptoethanol) at a 1:1 ratio. The samples were heated at $100^{\circ} \mathrm{C}$ for 4 to $5 \mathrm{~min}$ and each sample was loaded on an acrylamide gel ( $10 \%$ acrylamide for resolving gel and 5\% acrylamide for stacking gel) at the required volume to obtain $15 \mu \mathrm{g}$ of protein for protein detection. Wet blotting was used to transfer the proteins from the gel to a nitrocellulose membrane. The membrane was incubated with $10 \%$ milk in $0.1 \%$ PBST at room temperature for $1 \mathrm{~h}$ on a shaker in order to block non-specific binding. The primary antibodies were diluted in $1 \%$ milk in $0.1 \%$ PBST and incubated at $4{ }^{\circ} \mathrm{C}$ overnight with the membrane. The membrane was then washed three times for 10 min each time with $0.1 \%$ PBST in order to remove the excess primary antibody. The membrane was incubated with secondary antibodies diluted in $1 \%$ milk in $0.1 \%$ TBST at room temperature for $1 \mathrm{~h}$. The excess secondary antibody was washed three times with $0.1 \%$ PBST as described above, and the membrane was exposed to ECL reagents (Thermo Fisher Scientific, Inc.). Finally, the signal was transferred to a film, which was developed in the dark.

The primary antibody dilutions that used were as follows: Cyclin D1 at 1:300, p53 at 1:500, p2 $1^{\mathrm{WAF} / \mathrm{CIP} 1}$ at $1: 200, \mathrm{NF}-\kappa \mathrm{B}$ at 1:500, JNK at 1:500 and $\mathrm{p}-\mathrm{JNK}^{\mathrm{Thr} 183 / \mathrm{Tyr} 185}$ at 1:500. The secondary antibody dilutions used were at 1:2,000 for anti-mouse and/or anti-rabbit antibodies.

Statistical analysis. The results are expressed as mean \pm standard deviation (SD) for at least three independent experiments.

\section{Results}

Synthesis and cytotoxicity of the novel pyridone and pyridine compounds. The precursor chalcone 4',6', dimethoxy, 3,4 methylene dioxy chalcone was synthesized by a Claisen-Schmidt condensation (Fig. 1A). This compound was used to prepare the pyridone 1 (Fig. 1A). Compound 1 was further used to yield an intermediate chloropyridine that was converted to the pyridine 2 via hydrogenolysis (Fig. 1B). The exact synthetic route that was used for the synthesis of 1 and 2 will be published in a separate article. In an initial approach to evaluate the antiproliferative effects of the two compounds, MTT assays were carried out in MCF-7 breast adenocarcinoma and HepG2 liver hepatoblastoma cells. The cells were treated with various concentrations of compounds covering a range of $0.08-20 \mu \mathrm{M}$ for $96 \mathrm{~h}$, and cell viability was assessed spectrophotometrically. Compound 1 was more active in inhibiting proliferation of cancer cells than compound 2 (Fig. 2). Generally, HepG2 cells appeared more sensitive to compound treatment than MCF-7 cells, in terms of the $\mathrm{IC}_{25}$ values (concentrations required for $25 \%$ inhibition of cell proliferation) (Fig. 2). The calculated $\mathrm{IC}_{50} \mathrm{~s}$ were $4.5 \pm 0.3$ and $7.5 \pm 0.1 \mu \mathrm{M}$ for 1 and 2 , respectively, in the HepG2 cell line and $6.3 \pm 0.4 \mu \mathrm{M}$ and $16 \pm 1.7 \mu \mathrm{M}$ in the MCF-7 cell line, respectively.

Compounds 1 and 2 induce G2/M phase arrest in MCF-7 and HepG2 cells. In order to provide more information on the mechanism of antiproliferative action of compounds 1 and 2 , the cells were treated with the compounds for $24 \mathrm{~h}$ and further subjected to cell cycle analysis. Initial investigations using phase contrast microscopy revealed doublets of cells floating following treatment of $15 \mu \mathrm{M}$ with either of the compounds for $24 \mathrm{~h}$ (data not shown). Cell cycle analysis using propidium iodide (PI) staining demonstrated that both compounds 1 and $2(15 \mu \mathrm{M})$ induced $\mathrm{G} 2 / \mathrm{M}$ arrest in MCF-7 and HepG 2 cells following $24 \mathrm{~h}$ of treatment, while it was evident that a small percentage of cells underwent apoptosis as demonstrated by the subG1 peak (Figs. 3 and 4). Treatment of HepG2 cells with compound 1 and/or 2 caused an increase from $24 \pm 2.2 \%$ (control) to $56 \pm 3.2 \%$ and 
$\mathbf{A}$<smiles>CC(=O)c1ccccc1</smiles>

B 1<smiles>COc1ccc(-c2cc(-c3ccc4c(c3)OCO4)cc(=O)[nH]2)c(OC)c1</smiles>

2<smiles>COc1ccc(-c2cc(-c3ccc4c(c3)OCO4)ccn2)c(OC)c1</smiles>

Figure 1. Chemical structures and synthetic routes of the compounds 1 and 2 .
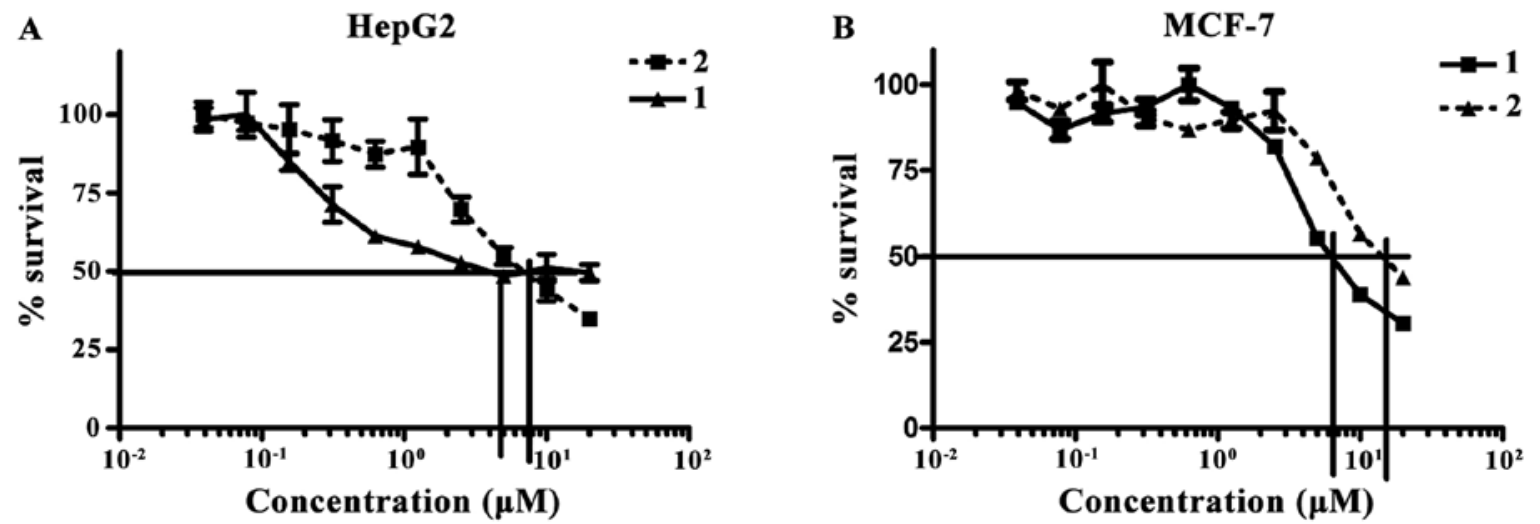

Figure 2. Cytotoxic effects of compounds 1 and 2 in (A) HepG2 and (B) MCF-7 cells. The compounds were incubated for $96 \mathrm{~h}$ at a concentration range of $0.078-20 \mu \mathrm{M}$, and cell viability was measured using the MTT assay. Error bars represent mean \pm SD for at least $\mathrm{n}=3$ determinations. SD, standard deviation.
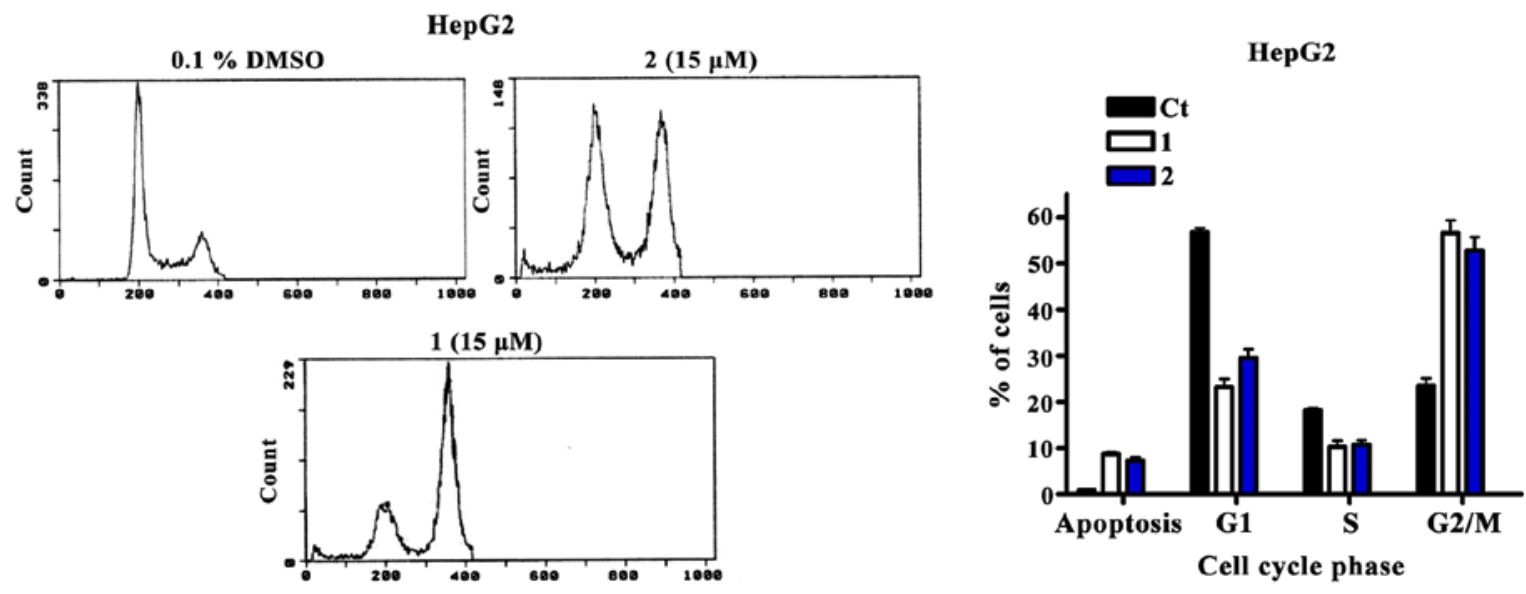

Figure 3. Cell cycle analysis of HepG2 cells treated with $15 \mu \mathrm{M}$ compound 1 and/or 2 for $24 \mathrm{~h}$. The cells were fixed in $70 \%$ ethanol and incubated with PI solution $(70 \mu \mathrm{g} / \mathrm{ml})$ containing RNase for 30 min. Fluorescence was measured using a Beckman-Coulter flow cytometer. Error bars represent mean $\pm \mathrm{SD}$ for $\mathrm{n}=3$ determinations. SD, standard deviation.

$51 \pm 3.8 \%$, respectively, of the cell population at the $\mathrm{G} 2 / \mathrm{M}$ phase, whereas a decrease was noted in the percentage of the cells at the G1 phase from $58 \pm 2.9 \%$ (control) to $23 \pm 2.2 \%$ and $28 \pm 3.1 \%$ for compound 1 and 2 respectively, compared with the control samples (Fig. 3). The percentage of cells undergoing apoptosis was estimated to $8 \pm 0.2 \%$ and $6.7 \pm 0.3 \%$ 

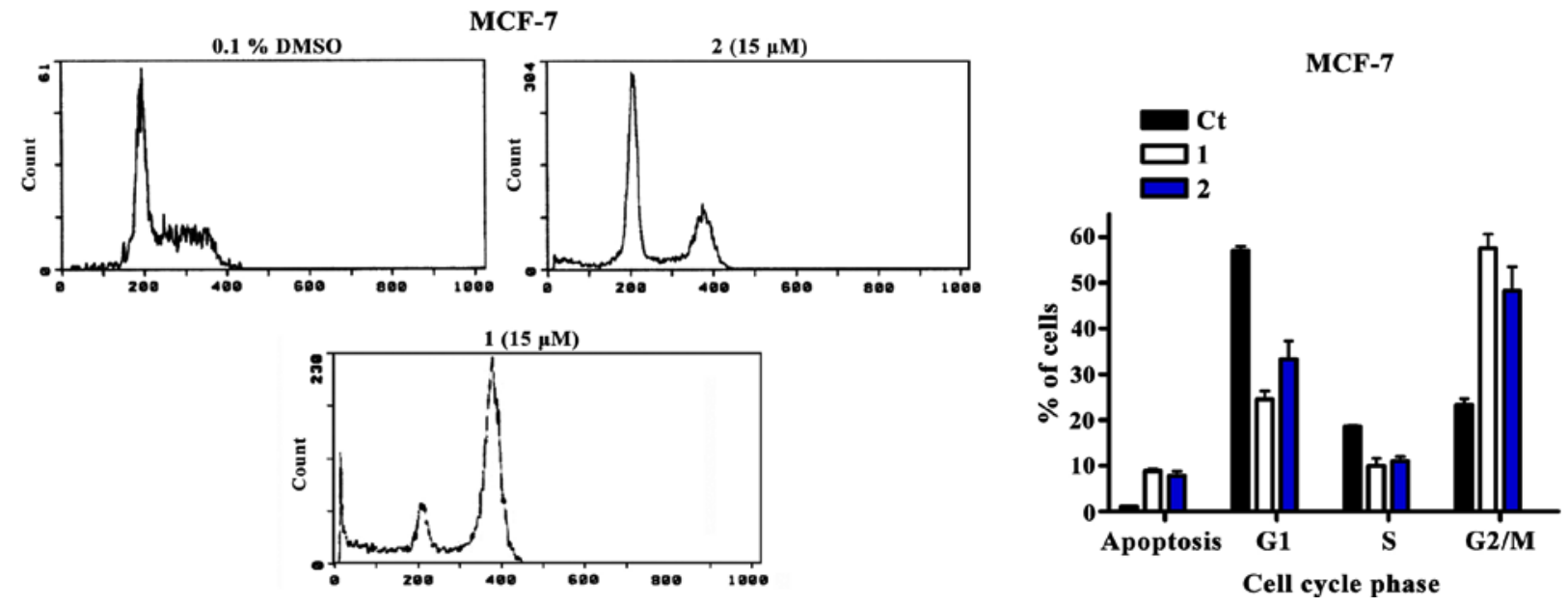

Figure 4. Cell cycle analysis of MCF-7 cells treated with $15 \mu \mathrm{M}$ compound 1 and/or 2 for $24 \mathrm{~h}$. The cells were fixed in $70 \%$ ethanol and incubated with PI solution $(70 \mu \mathrm{g} / \mathrm{ml})$ containing RNase for $30 \mathrm{~min}$. Fluorescence was measured using a Beckman-Coulter flow cytometer. Error bars represent mean $\pm \mathrm{SD}$ for $\mathrm{n}=3$ determinations. $\mathrm{SD}$, standard deviation.

for compounds 1 and 2, respectively (Fig. 3). Compound 2 was somewhat less potent than compound 1 in inducing apoptosis and the G2/M block and, as a lower increase in the cell cycle distribution of the liver cancer cells was noted (Fig. 3). Similar results were noted for the MCF-7 cell line, although 2 appeared less potent in those cells compared with HepG2 cells (23) (Fig. 4, G2/M arrest: Control, 23 $\pm 1.3 \%$, 1, $58 \pm 3.5 \% ; 2,47 \pm 4.7 \%)$. The data derived from the cell cycle analysis were in agreement with the results obtained from the MTT cell viability assays.

Compounds 1 and 2 induce upregulation of p53 and JNK in HepG 2 cells. In order to add insight to the mechanism of 1- and 2-mediated cell cycle inhibitory action, the protein expression of the cell cycle inhibitors and cell cycle-associated proteins following treatment of HepG2 liver cancer cells with the compounds was investigated. The investigation was focused on HepG2 cells, since they were more profoundly affected by the compounds compared with MCF-7 cells. The effects of compounds 1 and 2 on the proteins cyclin D1, p53 and p21 were evaluated. The data presented in this report indicated that both compounds 1 and 2 induced p53 expression in a concentration-dependent manner in HepG 2 cells. Furthermore, the induction of $\mathrm{p} 21^{\mathrm{WAF} / \mathrm{CIP} 1}$ was lower than that noted for $\mathrm{p} 53$. Compound 2 induced a weak increase in $\mathrm{p} 21^{\mathrm{WAF} / \mathrm{CIP} 1}$ protein expression in HepG2 cells. Moreover, the expression of the protein cyclin D1 was profoundly decreased in the presence of compounds 1 and 2 (Fig. 5A), which is in concordance with the decrease in the percentage of HepG2 cells at the G1 phase, since this protein is involved in the G1/S phase transition.

In order to elucidate the molecular mechanism underlying the induction of apoptosis in the presence of compounds 1 and 2, we examined the effects of these two compounds on the expression of the cell signaling proteins JNK and $\mathrm{NF}-\kappa \mathrm{B}$. Treatment of HepG 2 cells with compound 1 and/or $2(20-50 \mu \mathrm{M})$ for $24 \mathrm{~h}$ resulted in an upregulation of total JNK protein and total p-JNK ${ }^{\mathrm{T} 183 / 185}$ (Fig. 5). In contrast to compound 1 , compound 2 caused only an upregulation of total $\mathrm{JNK}$, while the levels of total $\mathrm{p}-\mathrm{JNK}^{\mathrm{T} 183 / 185}$ remained relatively constant (Fig. 5A). In order to investigate the expression pattern
A

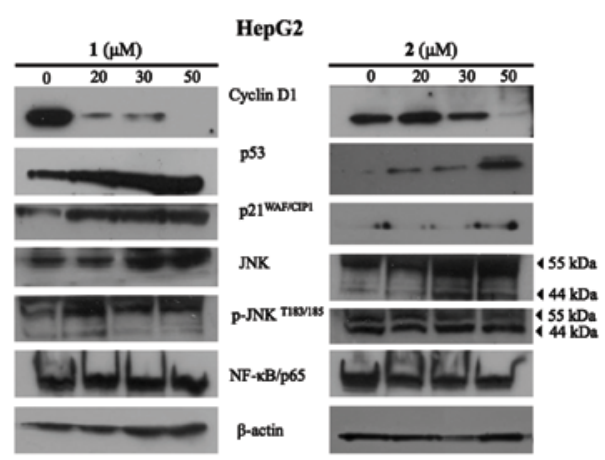

B

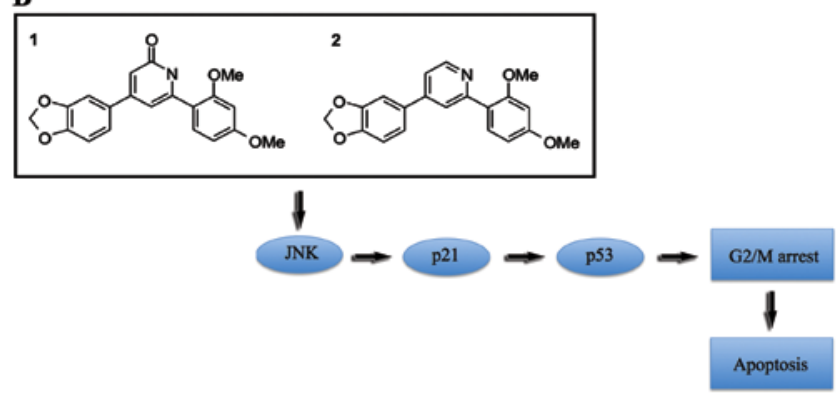

Figure 5. Induction of cell cyrcle associated proteins by compounds 1 and 2 . (A) Western blot analysis of cell cycle-associated and apoptosis-associated proteins. HepG2 cells were treated with compounds 1 and/or 2 at a concentration range of $20-50 \mu \mathrm{M}$ for $24 \mathrm{~h}$, and expression of the proteins was determined using immunoblotting. (B) Schematic pathway depicting the cell signaling events of compounds 1 and 2 in HepG2 cells.

of upstream mediators of JNK, we incubated HepG2 cells with compounds 2 and 1 and examined the expression of $N F-\kappa B$ using western blot analysis. NF- $\kappa \mathrm{B}$ is a transcription factor that is activated in response to stress and cytokines. This protein is overexpressed in certain cancer types and can lead to apoptosis via cell signaling with JNK proteins. The results indicated that the NF- $\kappa \mathrm{B}$ protein levels did not change following treatment with either compounds 1 and/or 2 (Fig. 5A), thus implying that induction of apoptosis in HepG 2 cells does not require $N F-\kappa B$ signaling (Fig. 5B). 


\section{Discussion}

Inhibition of cellular proliferation and induction of apoptosis is a commonly encountered phenomenon for the majority of phytochemicals and synthetic anticancer compounds. Particular attention has been given to natural and synthetic agents that induce the apoptotic cascade and/or arrest the cell cycle of cancer cells at specific checkpoints $(6,9,10)$. Chalcones have shown promising antitumor activity by 3 distinct modes of action: Antioxidant activity, cytotoxicity and induction of apoptosis. Recently, the exploration of structure-activity relationships has contributed towards the improvement of the anticancer properties of chalcones by substituting aryl rings and introducing heterocyclic moieties (11). Despite their promising antitumor activity, chalchones are frequently susceptible to photoisomerization in solution (12). Consequently, the present study explored the possibility of synthesizing novel pyridine and pyridone compounds from a chalchone precursor in order to overcome the non-specific photoisomerization. Compounds 1 and 2 were further evaluated in human cancer cells and it was demonstrated that they were more active in HepG2 liver cancer cells with $\mathrm{IC}_{50} \mathrm{~s}$ near the $\mu \mathrm{M}$ range, whereas their mechanism of action involved induction of $\mathrm{G} 2 / \mathrm{M}$ arrest and apoptosis via upregulation of the cell cycle inhibitors p21 and p53 and the cell signaling protein JNK (Fig. 5B).

Previous studies have reported the anticancer activity of pyridine derivatives against several types of cancer cells. A series of 6-amino-5-cyano-1-7(3-ethylphenyl)-2-oxo4-substituted-1,2-dihydropyridine-3-carbo-nitriles 4a-p were synthesized and tested for in vitro anticancer activity against the Ehrlich Ascites Carcinoma (EAC) cell line and the liver human tumor cell line (HepG2) (13). These compounds demonstrated considerably low potency in inhibiting proliferation of HepG2 cells in terms of IC $_{50}$ values (20-75 $\left.\mu \mathrm{M}\right)$ compared with the compounds investigated in the present study (3). In addition, 2-pyridones that contain aromatic and heteroaromatic rings with $4 \mathrm{H}$-pyrans were considerably more active in a range of human cancer cell lines, namely MCF-7, HepG2 and A549 ( $\mathrm{IC}_{50}$ of $8,11.9$ and $15.8 \mu \mathrm{M}$, respectively) (14).

With regard to the potential mechanism of action of compounds that are structurally similar to 1 and 2, various modes of anticancer activity have been proposed, such as inhibition of histone deacetylases, inhibition of $\mathrm{Cdc} 7$ and inhibition of VEGFR (15-17). However, the mechanism of action that is more likely to be responsible for the antiproliferative activity of compound 1 and 2 is inhibition of the process of mitosis. This hypothesis is based partially on the data reported in the present study and on previous studies that have demonstrated antimitotic activity of compounds that resemble the structure of compounds 1 and 2. The bidentate iron chelator CP20 (deferiprone) resembles the structure of compounds 1 and 2 and has been shown to increase the number of rat and human hepatoma cells in the G2/M phase of the cell cycle (18). Similarly, the anticancer compound ABT-751 is a novel orally active antimitotic agent in phase II clinical development that exerts antivascular effects and its structure contains a pyridine ring and a phenol group (19). It is interesting to note the structural similarity of compounds 1 and 2 with colchicine that contains 2 six-membered carbon benzene rings and one 7-membered carbon ring. Based on this hypothesis, a recent study has demonstrated the antimitotic activity of a series of new pyridine derivatives structurally related to ABT-751 that were initially tested for their cytotoxic activity in vitro against the HCT-116 and HepG-2 cancer cell lines. The results indicated that one of the pyridine compounds exhibited higher cytotoxic activity than the reference antimitotic agent colchicine, against both tested cell lines, with $\mathrm{IC}_{50}$ of 0.52 and $1.40 \mu \mathrm{M}$, respectively, while in vitro inhibition of tubulin polymerization showed comparable efficacy with that of colchicine (20). The present study is in agreement with these findings, although additional in vitro assays are required to elucidate the exact mechanism of action of compounds 1 and 2 .

In addition to the inhibition of the mitotic process compounds 1 and 2 profoundly affected the expression of cell cycle and cell signaling proteins. The reduction in the levels of cyclin D1 and the increase in p21 and p53 that were caused by compounds 1 and 2 in HepG2 cells is expected due to the accumulation of the cells in the G2/M phase. Cyclin D1 is the dimerization partner of CDK4 that controls the phosphorylation of $\mathrm{Rb}$ and the $\mathrm{G} 1 / \mathrm{S}$ phase transition. p53 is a transcription factor that is induced in response to DNA damage and/or cellular stress. p53 controls the G2/M checkpoint by allowing sufficient repairs to occur before the cell enters mitosis. p53 can also cause induction of apoptosis when irreversible damage to DNA or the cell cycle machinery occurs (21). The data presented in this report indicate that both compounds 1 and 2 induced $\mathrm{p} 53$ expression in a concentration-dependent manner in HepG2 cells. The p53-mediated cell cycle arrest was promoted by induction of the cell cycle inhibitor p21 ${ }^{\text {WAF/CIP1 }}$ (Fig. 5).

Furthermore, compounds 1 and 2 increased the expression of JNK in HepG2 cells and 1 further induced the phosphorylation of this protein. C-jun $\mathrm{N}$ terminal kinases belong to the family of MAPK kinases and are activated in response to stress and inflammatory signals. The activation of the kinase domain of JNK requires its phosphorylation at specific residues Thr183 and Tyr185. Activated JNK translocates to the nucleus where it regulates the phosphorylation of several transcription factors such as p53, STAT3 and ATF-2 (22). Consequently, the phosphorylation of JNK that was caused by compound 1 may be associated with the induction of p53 that in turn arrests the cells at the G2/M phase.

It is important at this point to note that 1 and 2 displayed antiproliferative activities with dissimilar potencies, as determined by MTT assays, cell cycle analysis and western blot analysis. This leads to the conclusion that the keto group on the middle ring of the pyridine structure plays a prominent role in enhancing the antiproliferative activity of the compound. Specifically, this functional group led to an approximately 3 -fold increase in $\mathrm{IC}_{50}$ values in MCF-7 cells and a 2 -fold increase in HepG2 cells, respectively. In the present study, we did not determine the exact nature of this structure-activity relationship with regard to the mechanism of action of the two compounds. However, this is an issue that warrants further investigation in future studies.

In conclusion, the present study described for the first time the synthesis and biological evaluation of one novel pyridine and one novel pyridone-based anticancer agent. The data demonstrated that both compounds inhibited the prolifera- 
tion of human breast and liver cancer cells by inducing G2/M phase arrest via a p53-p21-mediated pathway and apoptosis via JNK upregulation. These initial in vitro results show promise for the further development of these compounds as anticancer agents and their biological evaluation in an in vivo study.

\section{References}

1. Draper L: Breast cancer: Trends, risks, treatments, and effects. AAOHN J 54: 445-451, quiz 452-453, 2006.

2. Jepsen P, Vilstrup H, Tarone RE, Friis S and Sørensen HT: Incidence rates of hepatocellular carcinoma in the U.S. and Denmark: Recent trends. Int J Cancer 121: 1624-1626, 2007.

3. Sirotnak FM, Zakowski MF, Miller VA, Scher HI and Kris MG: Efficacy of cytotoxic agents against human tumor xenografts is markedly enhanced by coadministration of ZD1839 (Iressa), an inhibitor of EGFR tyrosine kinase. Clin Cancer Res 6: 4885-4892, 2000.

4. Rao YK,Fang SH and Tzeng YM: Differential effects of synthesized 2'-oxygenated chalcone derivatives: Modulation of human cell cycle phase distribution. Bioorg Med Chem 12: 2679-2686, 2004.

5. Bandgar BP, Gawande SS, Bodade RG, Totre JV and Khobragade CN: Synthesis and biological evaluation of simple methoxylated chalcones as anticancer, anti-inflammatory and antioxidant agents. Bioorg Med Chem 18: 1364-1370, 2010.

6. Rao YK, Kao TY, Ko JL and Tzeng YM: Chalcone HTMC causes in vitro selective cytotoxicity, cell-cycle G1 phase arrest through $\mathrm{p} 53$-dependent pathway in human lung adenocarcinoma A549 cells, and in vivo tumor growth suppression. Bioorg Med Chem Lett 20: 6508-6512, 2010.

7. Roque A,Lima JC,Parola AJ and Pina F: Substitution and solvent effects in the chalcones isomerization barrier of flavylium photochromic systems. Photochem Photobiol Sci 6: 381-385, 2007.

8. Iwata S, Nishino T, Inoue H, Nagata N, Satomi Y, Nishino H and Shibata S: Antitumorigenic activities of chalcones (II). Photo-isomerization of chalcones and the correlation with their biological activities. Biol Pharm Bull 20: 1266-1270, 1997.

9. Yin F, Giuliano AE, Law RE and Van Herle AJ: Apigenin inhibits growth and induces $\mathrm{G} 2 / \mathrm{M}$ arrest by modulating cyclin-CDK regulators and ERK MAP kinase activation in breast carcinoma cells. Anticancer Res 21 (1A): 413-420, 2001.

10. Katiyar SK, Roy AM and Baliga MS: Silymarin induces apoptosis primarily through a p53-dependent pathway involving $\mathrm{Bcl}-2 / \mathrm{Bax}$, cytochrome c release, and caspase activation. Mol Cancer Ther 4: 207-216, 2005.

11. León-González AJ, Acero N, Muñoz-Mingarro D, Navarro I and Martín-Cordero C: Chalcones as promising lead compounds on cancer therapy. Curr Med Chem 22: 3407-3425, 2015.
12. Leydet Y, Batat P, Jonusauskas G, Denisov S, Lima JC, Parola AJ, McClenaghan ND and Pina F: Impact of water on the cis-trans photoisomerization of hydroxychalcones. J Phys Chem A 117: 4167-4173, 2013

13. El-Said MS, El-Gazzar MG, Al-Dosari MS and Ghorab MM: Synthesis, anticancer activity and radiosensitizing evaluation of some new 2-pyridone derivatives. Arzneimittelforschung 62: 149-156, 2012.

14. Buduma K, Chinde S, Arigari NK, Grover P, Srinivas KV and Kotesh Kumar J: Iodine catalyzed simple and efficient synthesis of antiproliferative 2-pyridones. Bioorg Med Chem Lett 26: 2159-2163, 2016.

15. Cho M, Choi E, Yang JS, Lee C, Seo JJ, Kim BS, Oh SJ, Kim HM, Lee K, Park SK, et al: Discovery of pyridone-based histone deacetylase inhibitors: Approaches for metabolic stability. ChemMedChem 8: 272-279, 2013.

16. Wu X, Zeng H, Zhu X, Ma Q, Hou Y and Wu X: Novel pyrrolopyridinone derivatives as anticancer inhibitors towards Cdc7: QSAR studies based on dockings by solvation score approach. Eur J Pharm Sci 50: 323-334, 2013.

17. Yan W, Huang Z, Wang Z, Cao S, Tong L, Zhang T, Wang C, Zhou L, Ding J, Luo C, et al: Discovery of 1,3-Diaryl-pyridones as potent VEGFR-2 inhibitors: Design, synthesis, and biological evaluation. Chem Biol Drug Des 87: 694-703, 2016.

18. Lescoat G, Chantrel-Groussard K, Pasdeloup N, Nick H, Brissot $\mathrm{P}$ and Gaboriau F: Antiproliferative and apoptotic effects in rat and human hepatoma cell cultures of the orally active iron chelator ICL670 compared to CP20: A possible relationship with polyamine metabolism. Cell Prolif 40: 755-767, 2007.

19. Segreti JA, Polakowski JS, Koch KA, Marsh KC, Bauch JL, Rosenberg SH, Sham HL, Cox BF and Reinhart GA: Tumor selective antivascular effects of the novel antimitotic compound ABT-751: An in vivo rat regional hemodynamic study. Cancer Chemother Pharmacol 54: 273-281, 2004.

20. Elmeligie S, Khalil NA, Ahmed EM and Emam SH: New 3-substituted-2-(4-hydroxyanilino) pyridine derivatives: Synthesis, antitumor activity and tubulin polymerization inhibition. Arch Pharm (Weinheim) 350: 350, 2017.

21. Agarwal ML, Taylor WR, Chernov MV, Chernova OB and Stark GR: The p53 network. J Biol Chem 273: 1-4, 1998.

22. Shimokawa N, Qiu CH, Seki T, Dikic I and Koibuchi N: Phosphorylation of JNK is involved in regulation of $\mathrm{H}(+)$-induced c-Jun expression. Cell Signal 16: 723-729, 2004.

This work is licensed under a Creative Commons Attribution-NonCommercial-NoDerivatives 4.0 International (CC BY-NC-ND 4.0) License. 